\title{
Different particle flow patterns from the airways after recruitment manoeuvres using volume-controlled or pressure- controlled ventilation
}

\author{
Ellen Broberg ${ }^{1}$, Leif Pierre ${ }^{1}$, Mohammed Fakhro ${ }^{2}$, Lars Algotsson ${ }^{1}$, Malin Malmsjö ${ }^{4}$, Snejana Hyllén ${ }^{1}$ and \\ Sandra Lindstedt ${ }^{2,3^{*}}$ (D)
}

\author{
* Correspondence: sandra. \\ lindstedt_ingemansson@med.lu.se \\ ${ }^{2}$ Department of Cardiothoracic \\ Surgery and Transplantation, Skane \\ University Hospital, Lund University, \\ Lund, Sweden \\ ${ }^{3}$ Wallenberg Center for Molecular \\ Medicine, Lund University, Lund, \\ Sweden \\ Full list of author information is \\ available at the end of the article
}

\begin{abstract}
Objectives: Noninvasive online monitoring of different particle flows from the airways may serve as an additional tool to assess mechanical ventilation. In the present study, we used a customised PExA, an optical particle counter for monitoring particle flow and size distribution in exhaled air, to analyse airway particle flow for three subsequent days. We compared volume-controlled ventilation (VCV) and pressure-controlled ventilation (PCV) and performed recruitment manoeuvres (RM).

Methods: Six animals were randomised into two groups: half received VCV before PCV and the other half received PCV before VCV. Measurements were taken daily for $1 \mathrm{~h}$ in each mode during three subsequent days in six fully anaesthetised domestic pigs. A RM was performed twice daily for $60 \mathrm{~s}$ at positive end-expiratory pressure (PEEP) of 10, 4 breaths/min and inspiratory-expiratory ratio (I:E) of 2:1. Measurements were taken for 3 min before the RM, 1 min during the RM and for 3 min after the RM. The particle sizes measured were between 0.48 and $3.37 \mu \mathrm{m}$.

Results: A significant stepwise decrease was observed in total particle count from day 1 to day 3 , and at the same time, an increase in fluid levels was seen.

Comparing VCV to PCV, a significant increase in total particle count was observed on day 2, with the highest particle count occurring during VCV. A significant increase was observed comparing before and after RM on day 1 and 2 but not on day 3. One animal developed ARDS and showed a different particle pattern compared to the other animals.

Conclusions: This study shows the safety and useability of the PEXA technique used in conjunction with mechanical ventilation. We detected differences between the ventilation modes VCV and PCV in total particle count without any significant changes in ventilator pressure levels, $\mathrm{FiO}_{2}$ levels or the animals' vital parameters. The findings during RM indicate an opening of the small airways, but the effect is short lived. We have also showed that VCV and PCV may affect the lung physiology differently during recruitment manoeuvres. These findings might indicate that this technique may provide more refined information on the impact of mechanical ventilation.
\end{abstract}




\section{Background}

Mechanical ventilation is a lifesaving treatment that also can inflict lung damage such as acute lung injury (ALI) and ventilator-induced lung injury (VILI). The main concern is avoiding lung injury, both barotrauma (pressure-induced injury) and volume-trauma, in patients treated with mechanical ventilation. To reduce the risk of ALI and VILI, previous studies have shown that pressure-controlled ventilation (PCV) might be preferable to volume-controlled ventilation ( $\mathrm{VCV}$ ) but the studies are not conclusive [1-4]. During mechanical ventilation, recruitment manoeuvres (RM) are frequently used, but their efficacy and risks is an area of intense debate, especially in the most vulnerable groups of patients, such as those with acute respiratory distress syndrome (ARDS). The optimal RM has not yet been determined, nor has the optimal time during the course of mechanical ventilation that the RM should be performed [5-7]. In this study, we have focused on comparing VCV and PCV, along with comparing a gentle RM used during both VCV and PCV.

In clinical practice, airways are monitored by measuring pressure, volume and airflow. We have earlier described a new method to monitor airways noninvasively by analysing different particle flow and size distribution online during mechanical ventilation using an optical particle counter in a customised PExA device [8]. This study has been performed over a period of 3 days to establish the feasibility and safety of the PExA method to be used in conjunction with mechanical ventilation.

Exhaled breath particles (EBPs) are believed to be formed from the respiratory lining fluid in the distal parts of the lung during the opening and closing of the small airways and have been explored as potential markers for different lung diseases in spontaneously breathing patients [9-11]. Monitoring airways by analysing different particle flow online from the small airways may provide real-time insight into the effects of mechanical ventilation before changes in conventional parameters can be detected such as peak pressures, compliance and increased need of oxygen.

Different ventilation strategies during and after abdominal surgery have been studied, and the evidence suggests a protective ventilation with lower tidal volumes $(6-8 \mathrm{ml} / \mathrm{kg})$ and low levels of PEEP leading to fewer postoperative lung complications [12-15]. In this study, the animals underwent an initial abdominal surgery procedure to mimic a possible scenario in an intensive care unit in order to explore the impact of ventilation type by comparing optical particle counterflow and size patterns for two different ventilation modes, VCV and PCV, while using protective ventilation with tidal volumes of $6-8 \mathrm{ml} / \mathrm{kg}$ and PEEP of 5 during both modes.

Importantly, this study establishes the feasibility of monitoring particle count from intubated subjects on mechanical ventilation after major surgery over a period of $72 \mathrm{~h}$, investigating daily the impact of two different ventilation modes, VCV and PCV, as well as the particle pattern from the airways before, during and after a RM.

\section{Material and methods}

\section{Animal preparation}

The study was approved by the local Ethics Committee for Animal Research (Dnr 8401/2017). All animals received care according to the European Convention for the Protection of Vertebrate Animals used for Experimental and Other Scientific Purposes, 
as well as to the USA Principles of Laboratory Animal Care of the National Society for Medical Research, and the Guide for the Care and Use of Laboratory Animals, published by the National Academies Press (1996).

Six Swedish landrace pigs with a mean weight of $63 \pm 1.4 \mathrm{~kg}$ were fasted overnight with free access to water. Premedication was performed with an intramuscular injection of Xylazine (Rompun ${ }^{\circ}$ vet. $20 \mathrm{mg} / \mathrm{ml}$; Bayer AG, Leverkusen, Germany; $2 \mathrm{mg} / \mathrm{kg}$ ) mixed with ketamine (Ketaminol ${ }^{\circ}$ vet. $100 \mathrm{mg} / \mathrm{ml}$; Farmaceutici Gellini S.p.A., Aprilia, Italy; $20 \mathrm{mg} / \mathrm{kg}$ ) in their stables, and a peripheral IV access was established in the earlobe. The pig was then transferred to the laboratory and placed in a supine position on the operating table. Oral intubation was performed using a 7.5-size endotracheal tube after anaesthesia induction with sodium thiopental (Pentothal; Abbott Laboratories, North Chicago, Illinois, USA) and pancuronium bromide (Pavulon; N.V. Organon, Oss, the Netherlands). Anaesthesia was maintained with a ketamine (Ketaminol ${ }^{\circ}$ vet), midazolam (Midazolam Panpharma ${ }^{\circ}$, Oslo, Norway) and fentanyl (Leptanal ${ }^{\circ}$, Lilly, France) infusion. Fluid loss was compensated for by continuous infusion of Ringer's acetate. Mechanical ventilation was established with a Siemens-Elema ventilator (Servo Ventilator 300, Siemens, Solna, Sweden).

The animals were carefully turned on the sides about $30^{\circ}$ in each direction according to a schedule to reduce the risk of atelectasis.

\section{Abdominal surgery}

A laparotomy was performed to mimic a clinical situation in an intensive care unit with mechanical ventilation on the subject with no previous lung injury, and all animals had a secondary temporary closure with negative pressure wound therapy (NPWT) in a standard way. A $30-\mathrm{cm}$-long midline incision was performed on each pig. The V.A.C. Abdominal Dressing ( $\mathrm{KCI}^{\circ}$, Inc., San Antonio, TX, USA) was used. The visceral protective layer was cut to an approximate size of $35 \mathrm{~cm}$ wide and $35 \mathrm{~cm}$ long, extending into the paracolic gutters on both sides. A layer of polyurethane Granu Foam was placed on top of the visceral protective layer between the edges of the wound. The wound was covered with a self-adhesive polyethylene drape, and a track pad was inserted through the drape (all from V.A.C., KCI, San Antonio, TX), and then connected to a continuous vacuum source with a negative pressure of $-120 \mathrm{mmHg}$. No manipulation of the abdominal organs was made.

\section{Mechanical ventilation and pulmonary recruitment manoeuvre}

All animals had endotracheal tubes size 7.5, ventilator settings with tidal volume of 6 $\mathrm{ml} / \mathrm{kg}$, positive end-expiratory pressure of $5 \mathrm{cmH}_{2} \mathrm{O}$ and end-inspiratory pressures $<25$ $\mathrm{cmH}_{2} \mathrm{O}$ with an inspiratory to expiratory ratio (I:E) of 1:2. These settings remained unchanged during the study period. Particle outflow was measured using a modified PExA 2.0 instrument (PExA, Gothenburg, Sweden) each day during two different ventilation modes: VCV and PCV.

The animals were randomised into two different groups: one group received VCV before PCV $(n=3)$ and the other group received PCV before VCV $(n=3)$. Each animal was monitored during VCV and PCV for $1 \mathrm{~h}$ each per day. Before the collection period began for the second ventilation mode, there was an equilibration period of $30 \mathrm{~min}$ with the second ventilation mode. Twice daily, a RM was performed for $60 \mathrm{~s}$ at PEEP 
10, 4 breath/min and I:E 2:1. Measurements were done $3 \mathrm{~min}$ before the RM, $1 \mathrm{~min}$ during the RM and 3 min after the RM.

\section{PExA measurements}

The PExA 2.0 instrument (PExA, Gothenburg, Sweden) conducts measurements by optical particle counter and has been previously described in conjunction with mechanical ventilation. The instrument was connected to the outflow air of the mechanical respiratory circuit. The total accumulated number of particles from the airways was continuously measured by the PExA instrument during the two different ventilation modes each day. PExA measurements were made starting on day 1 until termination of mechanical ventilation on day 3. Measurements were made during each ventilation mode (VCV or PCV), each lasting $1 \mathrm{~h}$ in duration per day. Additionally, we monitored particle flow before, during and after RMs. The total particle count was measured for 3 min before the RM, for $1 \mathrm{~min}$ during the RM and for $3 \mathrm{~min}$ after the RM. Particles in the diameter range of $0.41-4.55 \mu \mathrm{m}$ were measured by the PExA instrument. The particles are computationally divided into eight different size distributions according to their mean diameter. The PExA instrument does not take into count if the particles are proteins or lipids, endogenous or exogenous, the instrument measures only the particles diameter, no matter what the particles origin is. In this study, we only present the particles according to their mean diameter and not their physiological abilities. The mean diameter of the particles are as follows: particle 1, $0.48 \mu \mathrm{m}$; particle size 2, $0.59 \mu \mathrm{m}$; particle size 3, $0.75 \mu \mathrm{m}$; particle size $4,0.98 \mu \mathrm{m}$; particle size $5,1.22 \mu \mathrm{m}$; particle size 6 , $1.67 \mu \mathrm{m}$; particle size 7, $2.52 \mu \mathrm{m}$; and particle size $8,3.37 \mu \mathrm{m}$.

\section{Blood gases and haemodynamic parameters}

All animals had a central venous catheter (CVC). The blood gases were drawn from the CVC and analysed in a standard way. Haemodynamic parameters were continuously recorded in a standard way.

\section{Experimental timeline}

Mechanical ventilator settings were named as follows: VCV day $1\left(\mathrm{VCV}_{1}\right), \mathrm{VCV}$ day 2 $\left(\mathrm{VCV}_{2}\right), \mathrm{VCV}$ day $3\left(\mathrm{VCV}_{3}\right), \mathrm{PCV}$ day $1\left(\mathrm{PCV}_{1}\right), \mathrm{PCV}$ day $2\left(\mathrm{PCV}_{2}\right)$ and $\mathrm{PCV}$ day $3\left(\mathrm{PCV}_{3}\right)$.

\section{Calculations and statistics}

Descriptive statistics, in the form of the number of patients, mean and the standard error of the mean (SEM) for the different parameters were analysed. The results are presented for the different parameters divided into the different groups. Statistically significant differences between the groups were tested using a paired Student $t$ test. All statistical analyses were performed, using GraphPad Prism Software, CA, USA. Significance was defined as $\left.\left.p<0.001{ }^{(* * *)}\right), p<0.01{ }^{(* *)}\right), p<0.05{ }^{(*)}$ ), and $p>0.05$ (not significant, n.s.).

\section{Results}

Animals

Pre-operative venous oxygen saturation $\left(\mathrm{SvO}_{2}\right)$ at a $\mathrm{FiO}_{2}$ of 0.5 was $60.5 \pm 6 \mathrm{kPa}$ with a saturation of $98 \pm 1 \%$. Baseline mean blood pressure and pulse was $81 \pm 3 \mathrm{mmHg}$ and 
$79 \pm 12$ beats per minute, respectively. No anatomical anomalies, signs of infection or malignancy were found in any of the animals at autopsy. One animal developed ARDS and was excluded and will be presented separately.

\section{Feasibility of the PExA method used in conjugation with mechanical ventilation}

This study has been performed as a feasibility study. No adverse events (mild, moderate or severe) as airway leakage, signs of rebreathing, altered pressure levels and haemodynamic interferences were seen. Ventilator peak pressures and mean pressures along with $\mathrm{FiO}_{2}$ levels, venous blood gases, blood pressure, saturation and pulse are shown in Tables 1, 2 and 3. Interestingly, we have not detected any statistic significant or clinically significant changes during the 3 days.

\section{Effects of mechanical ventilation on total particle count from the airways}

VCV and PCV were measured on a daily basis from day 1 until day 3 in all animals. On day 1 , the total particle count was $45,063 \pm 8775$; on day 2 , the total particle count was $30,749 \pm 6033$; and on day 3 , the total particle count was $18,409 \pm 3693$. Comparing day 1 and day 2, a significant difference was found $(p=0.0274)$. A significant decrease in particle flow was seen on day 3 compared to day $2(p=0.0246)$ (Fig. 1). One animal was excluded due to the development of clinical signs of ARDS, and the particle count from the airways in this animal was much higher than in the other animals.

Table 1 Hemodynamics parameters at the start and at the end of the daily measurements during volume-controlled ventilation (VCV)

\begin{tabular}{lllllll}
\hline & Start VCV & End VCV & Start VCV & End VCV & Start VCV & End VCV \\
& Day 1 & Day 1 & Day 2 & Day 2 & Day 3 & Day 3 \\
\hline Blood gases & & & & & & \\
SCvO2 & $61 \pm 7$ & $57 \pm 6$ & $77 \pm 4$ & $79 \pm 3$ & $82 \pm 3$ & $79 \pm 3$ \\
pH & $7.31 \pm 0.01$ & $7.32 \pm 0.01$ & $7.35 \pm 0.02$ & $7.33 \pm 0.03$ & $7.36 \pm 0.04$ & $7.37 \pm 0.02$ \\
Bicarbonate & $29 \pm 1$ & $30 \pm 1$ & $27 \pm 1$ & $27 \pm 1$ & $25 \pm 2$ & $27 \pm 1$ \\
Base excess & $6.3 \pm 1.4$ & $3.5 \pm 0.6$ & $3.9 \pm 0.6$ & $3.5 \pm 0.6$ & $1.1 \pm 2.6$ & $3.9 \pm 0.9$ \\
Lactate & $1.4 \pm 0.3$ & $1.2 \pm 0.2$ & $0.5 \pm 0.1$ & $0.5 \pm 0.1$ & $0.5 \pm 0.1$ & $0.6 \pm 0.1$ \\
Mechanical ventilation & & & & & & \\
Volume/minute & $7840 \pm 271$ & $7840 \pm 271$ & $7840 \pm 271$ & $7840 \pm 271$ & $7840 \pm 271$ & $7840 \pm 271$ \\
Breath/minute & $20 \pm 0$ & $20 \pm 0$ & $20 \pm 0$ & $20 \pm 0$ & $20 \pm 0$ & $20 \pm 0$ \\
PEEP & $5 \pm 0$ & $5 \pm 0$ & $5 \pm 0$ & $5 \pm 0$ & $5 \pm 0$ & $5 \pm 0$ \\
FiO2 & $0.5 \pm 0$ & $0.5 \pm 0$ & $0.5 \pm 0$ & $0.5 \pm 0$ & $0.5 \pm 0$ & $0.6 \pm 0.2$ \\
Pressure (peak) & $14 \pm 1$ & $15 \pm 1$ & $18 \pm 2$ & $17 \pm 2$ & $19 \pm 3$ & $20 \pm 3$ \\
Pressure (mean) & $7 \pm 1$ & $8 \pm 1$ & $8 \pm 1$ & $8 \pm 1$ & $8 \pm 1$ & $8 \pm 1$ \\
Haemodynamics & & & & & & $96 \pm \pm 2$ \\
Pulse & $77 \pm 11$ & $68 \pm 8$ & $72 \pm 4$ & $73 \pm 6$ & $86 \pm 15$ & $96 \pm 20$ \\
Systolic BP & $124 \pm 7$ & $111 \pm 7$ & $121 \pm 6$ & $119 \pm 8$ & $124 \pm 10$ & $127 \pm 13$ \\
Diastolic BP & $65 \pm 7$ & $70 \pm 6$ & $76 \pm 5$ & $73 \pm 6$ & $79 \pm 9$ & $85 \pm 16$ \\
Mean BP & $85 \pm 5$ & $83 \pm 6$ & $91 \pm 5$ & $88 \pm 6$ & $94 \pm 9$ & $99 \pm 15$ \\
Saturation & $97 \pm 1$ & $96 \pm 1$ & $95 \pm 1$ & $95 \pm 1$ & $95 \pm 1$ & $94 \pm 2$ \\
\hline
\end{tabular}


Table 2 Hemodynamics parameters at the start and at the end of the daily measurements during pressure-controlled ventilation (PCV)

\begin{tabular}{|c|c|c|c|c|c|c|}
\hline & Start PCV & End PCV & Start PCV & End PCV & Start PCV & End PCV \\
\hline & Day 1 & Day 1 & Day 2 & Day 2 & Day 3 & Day 3 \\
\hline \multicolumn{7}{|l|}{ Blood gases } \\
\hline $\mathrm{ScvO} 2$ & $58 \pm 7$ & $56 \pm 7$ & $78 \pm 2$ & $76 \pm 5$ & $87 \pm 4$ & $80 \pm 4$ \\
\hline $\mathrm{pH}$ & $7.34 \pm 0.02$ & $7.35 \pm 0.01$ & $7.32 \pm 0.02$ & $7.33 \pm 0.02$ & $7.36 \pm 0.01$ & $7.37 \pm 0.03$ \\
\hline Bicarbonate & $30 \pm 1$ & $29 \pm 1$ & $27 \pm 1$ & $27 \pm 1$ & $27 \pm 1$ & $27 \pm 1$ \\
\hline Base excess & $6.7 \pm 0.5$ & $7 \pm 1.2$ & $3.3 \pm 0.6$ & $4 \pm 0.7$ & $3.2 \pm 0.9$ & $4 \pm 0.9$ \\
\hline Lactate & $1.3 \pm 0.1$ & $1.4 \pm 0.2$ & $0.5 \pm 0.1$ & $0.5 \pm 0.1$ & $0.5 \pm 0.1$ & $0.5 \pm 0.1$ \\
\hline \multicolumn{7}{|c|}{ Mechanical ventilation } \\
\hline Volume/minute & $8000 \pm 294$ & $7840 \pm 271$ & $7840 \pm 271$ & $7840 \pm 271$ & $7840 \pm 271$ & $7840 \pm 271$ \\
\hline Breath/minute & $20 \pm 0$ & $20 \pm 0$ & $20 \pm 0$ & $20 \pm 0$ & $20 \pm 0$ & $20 \pm 0$ \\
\hline PEEP & $5 \pm 0$ & $5 \pm 0$ & $5 \pm 0$ & $5 \pm 0$ & $5 \pm 0$ & $5 \pm 0$ \\
\hline $\mathrm{FiO} 2$ & $0.5 \pm 0$ & $0.5 \pm 0$ & $0.5 \pm 0$ & $0.5 \pm 0$ & $0.6 \pm 0.1$ & $0.6 \pm 0.1$ \\
\hline Pressure (peak) & $15 \pm 1$ & $15 \pm 1$ & $16 \pm 1$ & $16 \pm 1$ & $19 \pm 2$ & $18 \pm 2$ \\
\hline Pressure (mean) & $8 \pm 1$ & $8 \pm 1$ & $8 \pm 1$ & $8 \pm 1$ & $8 \pm 1$ & $8 \pm 1$ \\
\hline \multicolumn{7}{|l|}{ Haemodynamics } \\
\hline Pulse & $81 \pm 15$ & $72 \pm 9$ & $74 \pm 7$ & $71 \pm 3$ & $101 \pm 20$ & $93 \pm 16$ \\
\hline Systolic BP & $108 \pm 8$ & $111 \pm 11$ & $121 \pm 9$ & $116 \pm 6$ & $132 \pm 13$ & $115 \pm 11$ \\
\hline Diastolic BP & $62 \pm 8$ & $61 \pm 7$ & $75 \pm 7$ & $68 \pm 7$ & $79 \pm 17$ & $63 \pm 9$ \\
\hline Mean BP & $77 \pm 7$ & $77 \pm 7$ & $90 \pm 7$ & $84 \pm 6$ & $96 \pm 15$ & $80 \pm 9$ \\
\hline Saturation & $96 \pm 1$ & $96 \pm 1$ & $95 \pm 1$ & $96 \pm 1$ & $92 \pm 3$ & $93 \pm 2$ \\
\hline
\end{tabular}

Effects of volume-controlled ventilation (VCV) and pressure-controlled ventilation (PCV)

VCV was compared to PCV from day 1 until day 3. On day 1 , the total particle count was 33,562 \pm 4951 during $\mathrm{VCV}_{1}$ and 56,564 $\pm 16,468$ during $\mathrm{PCV}_{1}(p=0.1779)$; on day 2 , the total particle count was 40,260 $\pm 10,097$ during $\mathrm{VCV}_{2}$ and 21,238 \pm 5625 during $\mathrm{PCV}_{2}(p=0.0184)$; and on day 3 , the total particle count was $18,343 \pm 5347$ during $\mathrm{VCV}_{3}$ and 18,497 \pm 5418 during $\mathrm{PCV}_{3}(p=0.5977)$ (Fig. 1).

\section{Particle distribution during VCV and PCV}

The total particle count from the airways is divided by the optical particle counter into eight different size distributions according to particle size where particle size 1 is the smallest and particle size 8 is the largest. The results of particle distribution from VCV and PCV modes during the three subsequent days are shown in Fig. 2. One animal developed severe ARDS on day 3 and had a different particle pattern from the airways from day 1 with significantly increased particle size 6 . Interestingly, on day 3, when the animal developed ARDS, the particle size 6 decreased. The animal that developed clinical signs of ARDS was excluded and is presented separately (Fig. 2).

\section{Recruitment manoeuvres (RM)}

The total particle count was measured 3 min before the RM, 1 min during the RM and 3 min after the RM. A RM was performed daily using VCV mode resulting in a total particle count of $379 \pm 106$ before, $1303 \pm 427$ during and $873 \pm 103$ after recruitment day 1 . Comparing the particle flow before and after RM, a significant difference was 
Table 3 Hemodynamics parameters before and after recruitement manoeuvres (RM) during the daily measurements

\begin{tabular}{lllllll}
\hline & $\begin{array}{l}\text { Before } \\
\text { Day 1 }\end{array}$ & $\begin{array}{l}\text { After } \\
\text { Day 1 }\end{array}$ & $\begin{array}{l}\text { Before } \\
\text { Day 2 }\end{array}$ & $\begin{array}{l}\text { After } \\
\text { Day 2 }\end{array}$ & $\begin{array}{l}\text { Before } \\
\text { Day 3 }\end{array}$ & $\begin{array}{l}\text { After } \\
\text { Day 3 }\end{array}$ \\
\hline Blood gases & & & & & & \\
ScvO2 & $58 \pm 4$ & $48 \pm 5$ & $82 \pm 2$ & $79 \pm 1$ & $82 \pm 2$ & $78 \pm 3$ \\
$\mathrm{pH}$ & $7.34 \pm 0.01$ & $7.33 \pm 0.01$ & $7.33 \pm 0.01$ & $7.32 \pm 0.01$ & $7.37 \pm 0.01$ & $7.35 \pm 0.02$ \\
Bicarbonate & $29 \pm 1$ & $30 \pm 1$ & $27 \pm 1$ & $27 \pm 1$ & $27 \pm 1$ & $26 \pm 1$ \\
Base excess & $7.0 \pm 0.5$ & $7.3 \pm 0.5$ & $3.4 \pm 0.3$ & $3.2 \pm 0.4$ & $3.5 \pm 0.5$ & $2.5 \pm 1.3$ \\
Lactate & $7.1 \pm 1.0$ & $1.2 \pm 0.2$ & $0.4 \pm 0.1$ & $0.4 \pm 0.1$ & $0.5 \pm 0.1$ & $0.5 \pm 0.1$ \\
Mechanical ventilation & & & & & & \\
Volume/minute & $7840 \pm 171$ & $7840 \pm 171$ & $7840 \pm 171$ & $7840 \pm 171$ & $8000 \pm 173$ & $8000 \pm 173$ \\
Breath/minute & $20 \pm 0$ & $20 \pm 0$ & $20 \pm 0$ & $20 \pm 0$ & $20 \pm 0$ & $20 \pm 0$ \\
PEEP & $5 \pm 0$ & $5 \pm 0$ & $5 \pm 0$ & $5 \pm 0$ & $5 \pm 0$ & $5 \pm 0$ \\
FiO2 & $0.5 \pm 0$ & $0.5 \pm 0$ & $0.5 \pm 0$ & $0.5 \pm 0$ & $0.5 \pm 0$ & $0.5 \pm 0$ \\
Pressure (peak) & $15 \pm 1$ & $14 \pm 1$ & $17 \pm 1$ & $16 \pm 1$ & $16 \pm 1$ & $16 \pm 1$ \\
Pressure (mean) & $8 \pm 1$ & $8 \pm 1$ & $8 \pm 1$ & $8 \pm 1$ & $8 \pm 1$ & $8 \pm 1$ \\
Haemodynamics & & & & & & \\
Pulse & $71 \pm 6$ & $67 \pm 5$ & $79 \pm 5$ & $78 \pm 2$ & $73 \pm 5$ & $70 \pm 4$ \\
Systolic BP & $112 \pm 5$ & $112 \pm 7$ & $123 \pm 4$ & $121 \pm 4$ & $118 \pm 8$ & $114 \pm 7$ \\
Diastolic BP & $64 \pm 5$ & $68 \pm 5$ & $76 \pm 4$ & $74 \pm 4$ & $71 \pm 6$ & $67 \pm 7$ \\
Mean BP & $80 \pm 4$ & $83 \pm 5$ & $92 \pm 4$ & $90 \pm 5$ & $87 \pm 6$ & $83 \pm 7$ \\
Saturation & $96 \pm 1$ & $96 \pm 1$ & $95 \pm 1$ & $95 \pm 1$ & $96 \pm 1$ & $96 \pm 1$ \\
\hline
\end{tabular}

observed ( $p=0.0001)$. Comparing the particle flow before and during RM $(p=0.0746)$, no significant difference was found. The total particle count was $918 \pm 281$ before, $2652 \pm 6$ during and $2692 \pm 995$ after recruitment day 2 . Comparing the particle flow before and after $\mathrm{RM}$, a significant difference was observed $(p=0.0476)$. Comparing the particle flow before and during RM, a significant increase could also be observed $(p=0.0161)$. On day 3 , the total particle count was $1357 \pm 366$ before, $1309 \pm 251$ during and $3359 \pm 1252$ after
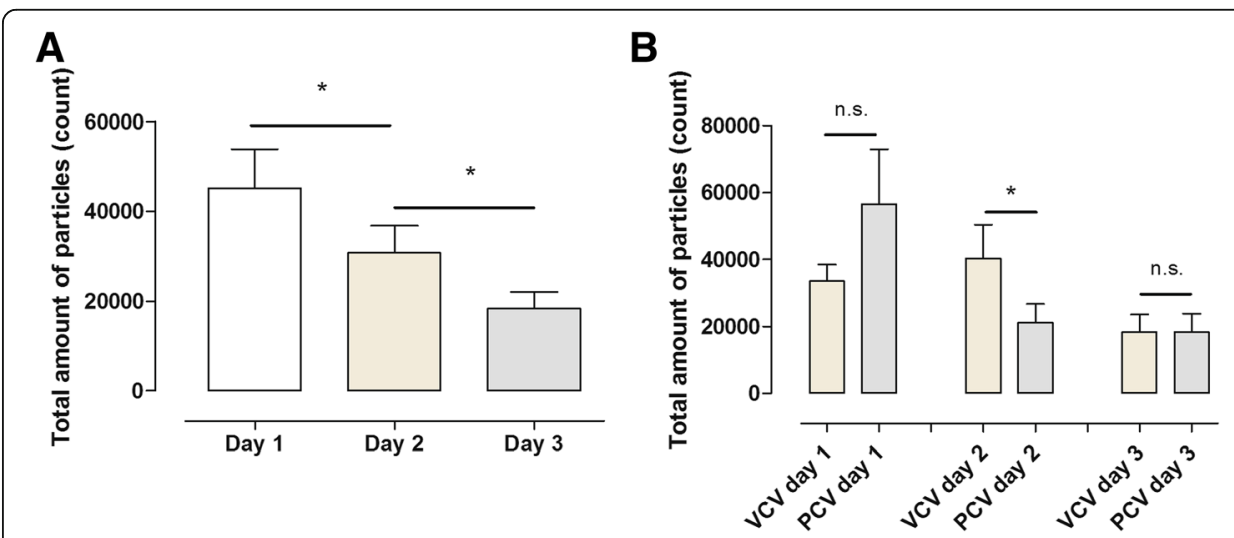

Fig. 1 The figure shows the total accumulated particle count measured by a customised PEXA instrument during volume-controlled ventilation (VCV) and pressure-controlled ventilation (PCV) during three consecutive days $(n=5)$ (a). In $\mathbf{b}$, VCV and PCV are divided into separate groups. Note the significant increase in total particle count on day 2 


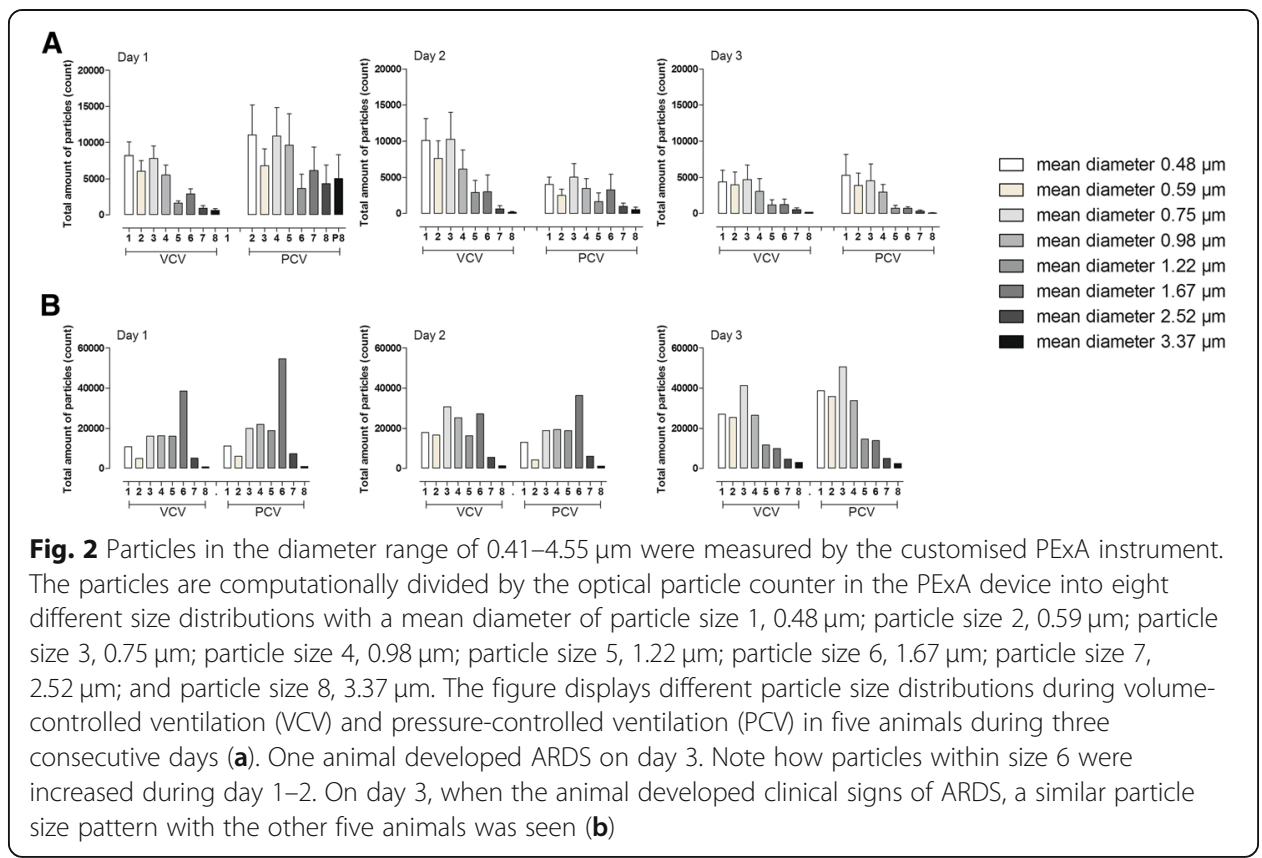

recruitment day 3. Comparing the particle flow before and after RM, no significant difference was observed $(p=0.0920)$. Comparing the particle flow before and during RM, no significant difference was observed ( $p=0.8577$ ) (Fig. 3).

A RM was performed daily using PCV mode, and the total particle count was $737 \pm$ 186 before, $146 \pm 22$ during and $923 \pm 212$ after recruitment day 1 . Comparing the particle flow before and after RM, no significant difference was observed $(p=0.0563)$. Comparing the particle flow before and during RM, a significant decrease was observed $(p=0.0083)$. The total particle count was $321 \pm 105$ before, $104 \pm 22$ during and $433 \pm$ 117 after recruitment day 2. Comparing the particle flow before and after RM, a

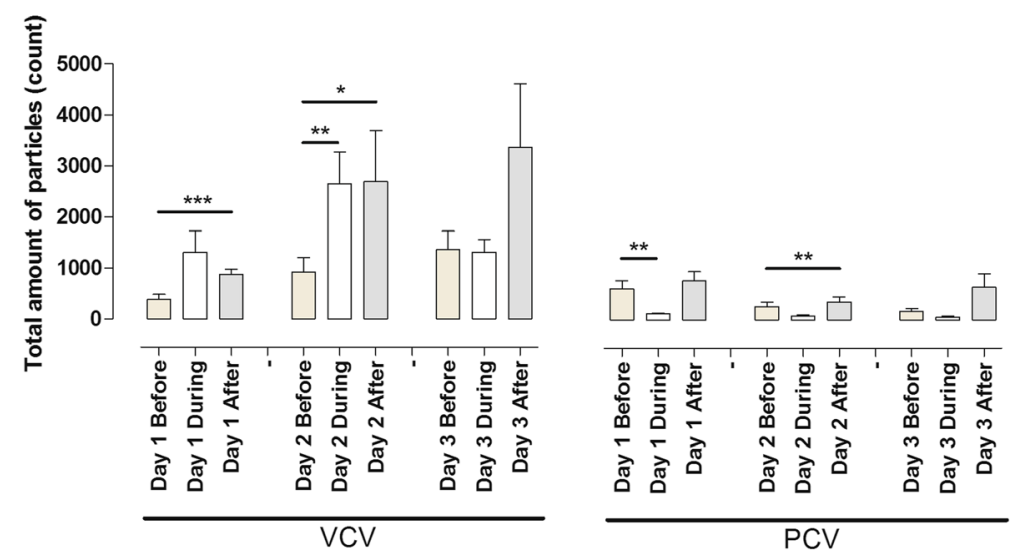

Fig. 3 All animals underwent recruitment manoeuvre (RM) twice daily starting on day 1 until day 3 . The total accumulated particle count was measured by PEXA 3 min before RM, 1 min during the RM and 3 min after RM. The figure shows the total particle count before, during and after RM for three consecutive days using volume-controlled ventilation (VCV) and pressure-controlled ventilation (PCV) 
significant increase was observed ( $p=0.0157)$. Comparing the particle flow before and during RM, no significant difference could be observed $(p=0.0520)$. On day 3 , the total particle count was $208 \pm 59$ before, $73 \pm 21$ during and $771 \pm 312$ after recruitment. Comparing the particle flow before and after RM, no significant difference was observed $(p=0.0565)$. Comparing the particle flow before and during RM $(p=0.0824)$, no significant difference was observed (Fig. 3).

Comparing particle flow for VCV with PCV before and after RM, a significant difference was found on day $1(p=0.0185)$ but not on day $2(p=0.0584)$ or day 3 ( $p=$ 0.3013). Particle flow during RM found significant differences on all three days: day 1 VCV vs day $1 \mathrm{PCV}(p=0.0232)$, day $2 \mathrm{VCV}$ vs day $2 \mathrm{PCV}(p=0.0016)$ and day $3 \mathrm{VCV}$ vs day 3 PCV ( $p=0.0112)$ (Fig. 4).

\section{Fluid balance}

The fluid balance was measured daily. On day 1 , the fluid balance was $0 \pm 0 \mathrm{ml}$; on day 2, the fluid balance was $968 \pm 193 \mathrm{ml}$; and on day 3, the fluid balance was $2498 \pm 275$ $\mathrm{ml}$. Statistical significance was found comparing day 1 and day $2(p=0.0014)$ and day 2 and day $3(p=0.0042)$ (Fig. 5).

\section{Blood gases, haemodynamics and mechanical ventilation settings}

The blood gases, haemodynamics and mechanical ventilation settings during the different ventilation settings and during the different days are shown in Tables 1 and 2. Measurements were taken at the start and at the end of each ventilation mode. In Table 3, the same parameters are shown and were taken $3 \mathrm{~min}$ before pulmonary recruitment and $3 \mathrm{~min}$ after RM. Fluid was given to maintain vital signs and an adequate urine output. All animals were stable during all measurements, and no significant changes in blood gases, haemodynamics or in mechanical ventilation settings could be found.

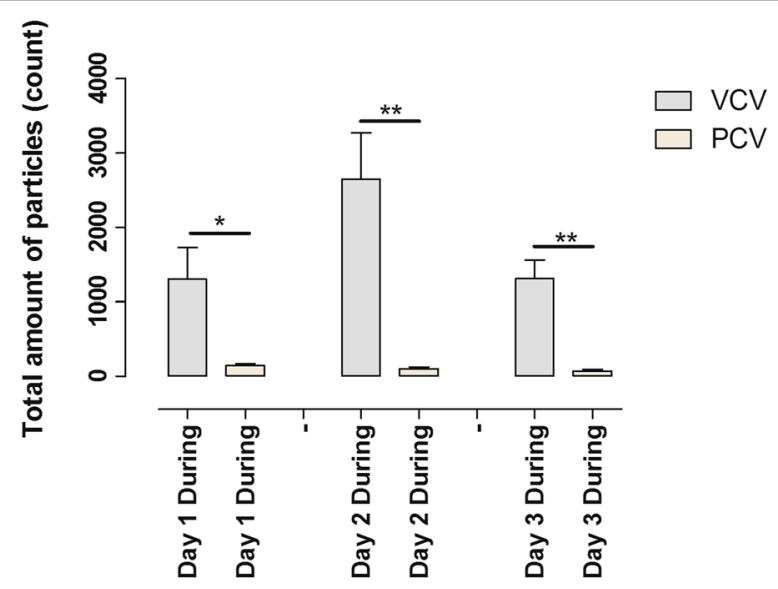

Fig. 4 A recruitment manoeuvre (RM) was performed on all animals twice daily starting on day 1 until day 3. The total accumulated particle count was measured by PExA during the RM for $1 \mathrm{~min}$. The figure shows the total particle count during RM during three consecutive days comparing volume-controlled ventilation (VCV) and pressure-controlled ventilation (PCV). Note the significant differences in total particle count during VCV and PCV before the actual RM 


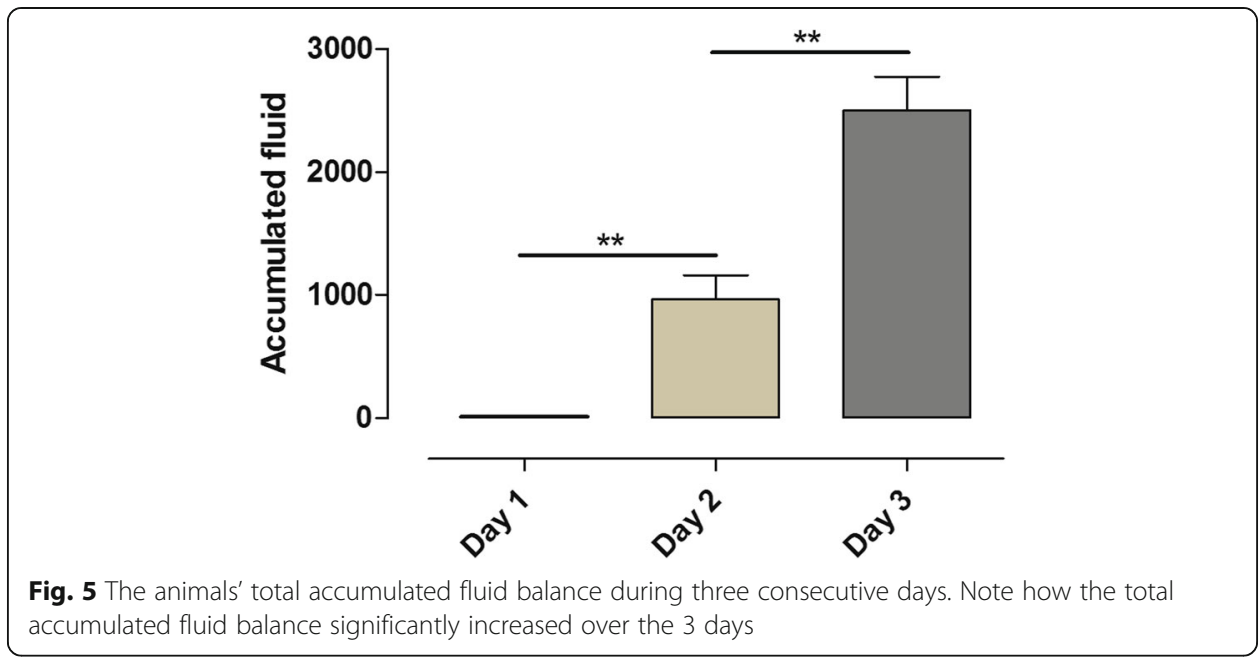

\section{Discussion}

The main techniques to monitor patients' airways during mechanical ventilation are by pressure, volume and airflow. Noninvasive online analysis of different particle flow from the airways might provide an additional tool for monitoring the patient during mechanical ventilation. We have recently shown in a lung transplantation animal model that different ventilation modes resulted in different particle flow from the airways in vivo, post mortem and during ex vivo lung perfusion [8]. Exhaled breath particles (EBPs) are believed to originate from the respiratory tract lining fluid (RTLF). The RTLF consists of heterogenous group of substances covering the epithelial wall of the airways and has a different composition in different parts of the airways. The exact origin and formation of all particles in the airway are not fully clear, but what is known is that surfactant A is a large component produced in the alveoli by type II alveolar cells. Surfactant A's composition is of phospholipids, proteins, peptides and nucleic acids. The RTLF also contains glycoproteins and mucins predominantly from the conducting airways. Studies have shown that an altered composition of the RTLF might reflect different airway diseases [11, 16-19]. Since the animals are intubated and on mechanical ventilation, the PExA instrument is not in contact with particles originating from the mouth and nasopharynx, but still, some of the conducting airways are below the endotracheal tube.

Mechanical ventilation is used in several clinical conditions in an intensive care unit. Lung-protective ventilation strategies with the use of low tidal volume and low to moderate PEEP have been shown to improve outcomes in patients with or at risk for ARDS [20], but also in patients without pre-existing lung injury, using low tidal volume and moderate PEEP has also proven beneficial [21]. Mechanical ventilation, particularly high tidal volume and the use of very low PEEP or no PEEP at all, increases the collapse of the distal airways and the alveoli, and this is known to have a negative impact on lung function not only in ARDS patients but in patients with healthy lungs. In order to prevent collapse of the airways, ARDSnet suggests different levels of PEEP, according to the open lung concept, that have shown favourable outcome with improved pulmonary function without causing further harm [22]. In the present study, we follow the recommendations from ARDSnet by using low tidal volumes and moderate PEEP and 
studying if there is any difference in particle flow when comparing two commonly used ventilation modes, VCV and PCV. All animals underwent a laparotomy on day 1 before any PExA measurements were made to mimic a clinical situation in an intensive care unit in subjects with no previous lung injury, and all animals thereafter were studied for three consecutive days. All animals were fully anaesthetised, and no animal drew their own breath.

\section{The PExA instrument is safe to use conjugation with mechanical ventilation}

This study has been performed as a feasibility study. No adverse events (mild, moderate or severe) as airway leakage, signs of rebreathing, altered pressure levels and haemodynamic interferences were seen. As shown in Tables 1, 2 and 3, we have not detected any significant changes during the 3 days. Furthermore, this study has not shown any harmful effects on the subjects either in ventilator measurements or haemodynamic measurements; thereby, we believe this technique can safely be used in conjugation with mechanical ventilation. The method has the potential to shed new light on the physiological changes within the lung during mechanical ventilation.

\section{Decreased particle flow in relation to increased fluid levels}

In all the animals, we noticed a stepwise significant decrease in total particle count during the 3 days (Fig. 1a). In studies with ARDS patients, it has been proven that excessive fluid overload leads to poorer outcome [23, 24]. Over the course of the 3 days, the animals in this study showed an increase in fluid levels as well as a decrease in total particle count (Figs. 1a and 5). We speculate that the decrease in total particle count may be due to the fluid overload in the alveoli.

\section{Lung response to different ventilation modes depending on time on mechanical ventilation}

Comparing the total particle count for VCV and PCV day by day during the 3 days, counting the particle flow from day 1 PCV had a higher particle count than VCV, but not significant. Interestingly, a similar reproducible pattern with higher particle flow for PCV compared to VCV has been described in a previous study [8]. On day 2, a significantly higher total particle count could be observed for VCV compared to PCV. Interestingly, on day 3, there was no difference between the two modes (Fig. 1b). During all the days, there were no changes in the commonly used indicators of lung function such as pressure levels, $\mathrm{FiO}_{2}$ levels or the animals' vital parameters. These findings may show that the different ventilation modes may have a greater impact and generate a different biochemical environment in the RTLF and EBP than currently understood.

\section{Altered composition in RTLF may correlate to airway disease}

The PExA instrument has the possibility to both measure particle count from the airways and divide the different particles according to eight different sizes, from 0.48 to $3.37 \mu \mathrm{m}$ in mean diameter. By studying the particle patterns according to size, it might give us additional information on the physiology of the small airways and the impact of mechanical ventilation. The composition between the eight different particle sizes had the same pattern when comparing the two different modes (Fig. 2a). In the animal that 
was excluded due to developing severe acute clinical signs of ARDS on day 3, but not on day 1 or day 2 , a very different particle pattern was observed compared to the other five animals, when studying the different size distributions divided by the PExA instrument. We could observe an increase of total particle count in both VCV and PCV mode for this animal compared to the others during all measurements on all the days. Interestingly, the pattern of particles size 6 with a mean diameter of $1.67 \mu \mathrm{m}$ stood out in particular, both in VCV and PCV compared to the other animals (Fig. 2b). To focus on particle size 6 , it had a severely increased particle count on day 1 and 2 when there were no clinical signs of ARDS, but on day 3, when the animal developed acute clinical signs of ARDS, particle size 6 was severely reduced compared to previous days, and the particle pattern for size 1-8 was similar to the other animals. We find this change in the composition of the EBP very interesting as it may be an early sign of developing lung injury.

\section{Recruitment manoeuvre (RM) opens up the alveoli, but the effect is short lived}

We performed a RM in all animals, every day in both ventilation modes. Measurement was done for $3 \mathrm{~min}$ before the RM, during $1 \mathrm{~min}$ of the RM and for $3 \mathrm{~min}$ after the RM. We could see an increase in the total particle count after the RM compared to before the RM in both VCV and PCV. We believe that the reason for these results is that the actual RM opens up the alveoli's and thereby a higher particle count (Fig. 3). We could also see that this effect of higher particle count was fairly short lived, and the effect was predominantly over within $2-3 \mathrm{~min}$.

\section{The lung physiology during RM is different depending on ventilation mode}

During the RM, a difference was observed in total particle count depending on what ventilation mode was used. In VCV, there was an increased total particle count during the RM compared to before the RM. In PCV, on the other hand, there was instead a decreased total particle count during the RM compared to before the RM. The total particle count during RM was higher in VCV compared to PCV during all the days (Fig. 4). We interpret these findings that increasing the PEEP to 10 does not have the same impact on the small airways for VCV and PCV, and we speculate that a RM during VCV leads to increased opening and closing of the small airways compared to PCV.

\section{Limitations}

This study is an experimental study and has been performed under controlled conditions in a laboratory setting in a small healthy cohort without underlying lung injury. The study has been performed as a feasibility study, and therefore, we have chosen to study a limited amount of ventilatory settings, and we have focused on two different modes and a gentle RM.

Changing tidal volumes, respiratory rate or I:E ratios might have given more evolving data, but as this is the first study in its kind, we wanted to focus on feasibility and safety. All pigs have been in a supine position throughout the study period, and that might have affected the result since this position for this long period of time may promote atelectasis. The pigs were turned on their side about $30^{\circ}$ according to a schedule 
to reduce the risk of atelectasis, and due to abdominal surgery and vacuum closure, another position would be very difficult to achieve.

The PExA instrument only detects particle in the diameter range of $0.41-4.55 \mu \mathrm{m}$ and there can be particles outside this range. The majority of particles originating from RTLF are presumably within this range. We have not studied if any particles have been deposited on the inside lining of the endotracheal tube or other parts of the respiratory circuit. A proportionate deposition of particles on the entire respiratory circuit between the different subjects could be assumed, since all the subjects were exposed to the same length of the respiratory circuit.

The particles from the airways were collected onto a membrane for subsequent biochemical analyses. On day 1 , we were able to collect significantly more mass of particles (mean size $24.8 \mathrm{ng}$ ) than on days 2 and 3; however, unfortunately, it was not sufficient for analyses with our current methods. We are currently trying to improve the analysing techniques. In spite of this, these findings may provide further understanding on the physiology of the small airways and the impact of mechanical ventilation.

\section{Conclusions}

This study has primarily been done as a feasibility study to assess the safety and useability of the PExA technique. We believe this study has been rudimental in proving that the PExA technique is safe to use in conjunction with mechanical ventilation both as single use but also repeatedly over days. The results indicate that different ventilation modes, such as VCV and PCV, may have a greater impact and generate a different biochemical environment in the small airways than currently understood. The findings during recruitment manoeuvres indicate an opening of the small airways, but the effect is short lived. We have also showed that VCV and PCV may affect the lung physiology differently during recruitment manoeuvres. During the 3 days, all animals showed a stepwise decrease in particle count and at the same time increased fluid levels, which might indicate a relationship between the particle count and the fluid levels, i.e., the more fluid overload, the less particle count. The animal that developed ARDS showed a different particle composition compared to the other animals, which might correlate to an alteration of the RTLF. Interestingly, we could detect differences in particle flow without any significant changes in ventilator pressure levels, FiO2 levels or the animals' vital parameters, and our interpretation is that this technique might very well give more detailed information about the impact of mechanical ventilation.

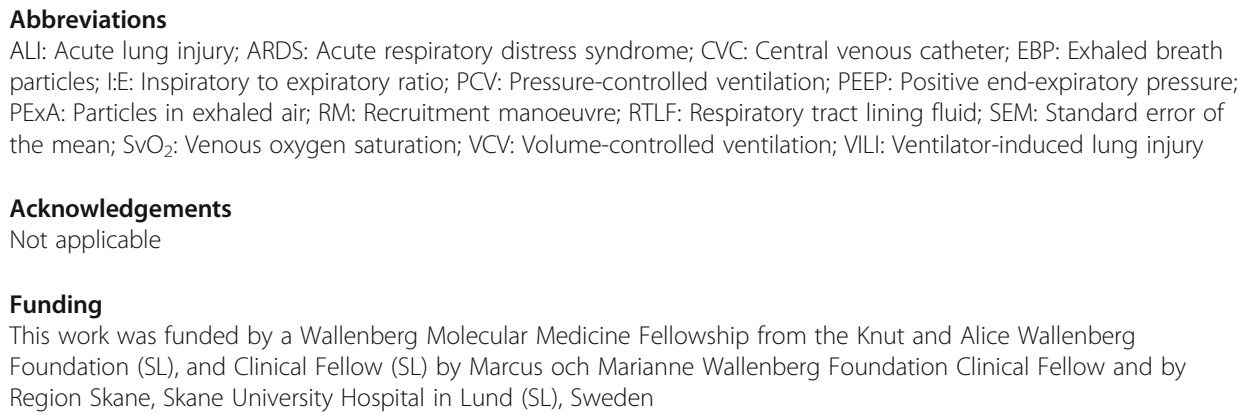


Authors' contributions

$S L, E B, S H$ and $L A$ participated in the design of the study. SL and EB wrote the application for the ethical approval. EB, $L P, S H$ and $S L$ carried out the experiments. SL, EB, LA, MM and MF analysed the study results. SL, EB and SH drafted the manuscript. All authors read and approved the final manuscript.

\section{Ethics approval}

The study was approved by the Ethics Committee for Animal Research, Lund University, Lund, Sweden Dnr 8401/2017. All animals received care according to the European Convention for the Protection of Vertebrate Animals used for Experimental and Other Scientific Purposes, as well as to the USA Principles of Laboratory Animal Care of the National Society for Medical Research, and the Guide for the Care and Use of Laboratory Animals, published by the National Academies Press (1996).

\section{Consent for publication}

Not applicable

\section{Competing interests}

The authors declare that they have no competing interests.

\section{Publisher's Note}

Springer Nature remains neutral with regard to jurisdictional claims in published maps and institutional affiliations.

\section{Author details}

${ }^{1}$ Department of Cardiothoracic Anaesthesia and Intensive Care, Skane University Hospital, Lund University, Lund, Sweden. ${ }^{2}$ Department of Cardiothoracic Surgery and Transplantation, Skane University Hospital, Lund University, Lund, Sweden. ${ }^{3}$ Wallenberg Center for Molecular Medicine, Lund University, Lund, Sweden. ${ }^{4}$ Department of Ophthalmology, Skane University Hospital, Lund University, Lund, Sweden.

Received: 18 December 2018 Accepted: 3 March 2019

Published online: 13 March 2019

\section{References}

1. Fan E, Brodie D, Slutsky AS (2018) Acute respiratory distress syndrome: advances in diagnosis and treatment. JAMA 319(7):698-710

2. Gao S, Zhang Z, Brunelli A, Chen C, Chen C, Chen G, Chen H, Chen JS, Cassivi S, Chai Y et al (2017) The Society for Translational Medicine: clinical practice guidelines for mechanical ventilation management for patients undergoing lobectomy. J Thorac Dis 9(9):3246-3254

3. Jiang J, Li B, Kang N, Wu A, Yue Y (2016) Pressure-controlled versus volume-controlled ventilation for surgical patients: a systematic review and meta-analysis. J Cardiothorac Vasc Anesth 30(2):501-514

4. Chacko B, Peter JV, Tharyan P, John G, Jeyaseelan L (2015) Pressure-controlled versus volume-controlled ventilation for acute respiratory failure due to acute lung injury (ALI) or acute respiratory distress syndrome (ARDS). Cochrane Database Syst Rev 1:CD008807

5. Goligher EC, Hodgson CL, Adhikari NKJ, Meade MO, Wunsch H, Uleryk E, Gajic O, Amato MPB, Ferguson ND, Rubenfeld $\mathrm{GD}$ et al (2017) Lung recruitment maneuvers for adult patients with acute respiratory distress syndrome. A systematic review and meta-analysis. Ann Am Thorac Soc 14(Supplement_4):S304-S311

6. Constantin JM, Godet T, Jabaudon M, Bazin JE, Futier E (2017) Recruitment maneuvers in acute respiratory distress syndrome. Ann Transl Med 5(14):290

7. Santos RS, Silva PL, Pelosi P, Rocco PR (2015) Recruitment maneuvers in acute respiratory distress syndrome: the safe way is the best way. World J Crit Care Med 4(4):278-286

8. Broberg E, Wlosinska M, Algotsson L, Olin AC, Wagner D, Pierre L, Lindstedt S (2018) A new way of monitoring mechanical ventilation by measurement of particle flow from the airways using Pexa method in vivo and during ex vivo lung perfusion in DCD lung transplantation. Intensive Care Med Exp 6(1):18

9. Larsson P, Larstad M, Bake B, Hammar O, Bredberg A, Almstrand AC, Mirgorodskaya E, Olin AC (2017) Exhaled particles as markers of small airway inflammation in subjects with asthma. Clin Physiol Funct Imaging 37(5):489-497

10. Beck O, Olin AC, Mirgorodskaya E (2016) Potential of mass spectrometry in developing clinical laboratory biomarkers of nonvolatiles in exhaled breath. Clin Chem 62(1):84-91

11. Almstrand AC, Ljungstrom E, Lausmaa J, Bake B, Sjovall P, Olin AC (2009) Airway monitoring by collection and mass spectrometric analysis of exhaled particles. Anal Chem 81(2):662-668

12. Watson X, Chereshneva M, Odor PM, Chis Ster I, Pan-London Perioperative A, Research N, Cecconi M (2018) Adoption of lung protective ventilation IN patients undergoing emergency laparotomy: the ALPINE study. A prospective multicentre observational study. Br J Anaesth 121(4):909-917

13. Serpa Neto A, Hemmes SN, Barbas CS, Beiderlinden M, Biehl M, Binnekade JM, Canet J, Fernandez-Bustamante A, Futier E, Gajic O et al (2015) Protective versus conventional ventilation for surgery: a systematic review and individual patient data meta-analysis. Anesthesiology 123(1):66-78

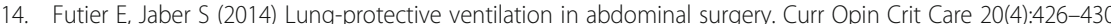

15. Severgnini P, Selmo G, Lanza C, Chiesa A, Frigerio A, Bacuzzi A, Dionigi G, Novario R, Gregoretti C, de Abreu MG et al (2013) Protective mechanical ventilation during general anesthesia for open abdominal surgery improves postoperative pulmonary function. Anesthesiology 118(6):1307-1321

16. Scheideler L, Manke HG, Schwulera U, Inacker O, Hammerle H (1993) Detection of nonvolatile macromolecules in breath. A possible diagnostic tool? Am Rev Respir Dis 148(3):778-784 
17. Koetzler R, Saifeddine M, Yu Z, Schurch FS, Hollenberg MD, Green FH (2006) Surfactant as an airway smooth muscle relaxant. Am J Respir Cell Mol Biol 34(5):609-615

18. Chiba H, Piboonpocanun S, Mitsuzawa H, Kuronuma K, Murphy RC, Voelker DR (2006) Pulmonary surfactant proteins and lipids as modulators of inflammation and innate immunity. Respirology 11(Suppl):S2-S6

19. Griese M (1999) Pulmonary surfactant in health and human lung diseases: state of the art. Eur Respir J 13(6):1455-1476

20. Slutsky AS, Ranieri VM (2000) Mechanical ventilation: lessons from the ARDSNet trial. Respir Res 1(2):73-77

21. Wolthuis EK, Choi G, Dessing MC, Bresser P, Lutter R, Dzoljic M, van der Poll T, Vroom MB, Hollmann M, Schultz MJ (2008) Mechanical ventilation with lower tidal volumes and positive end-expiratory pressure prevents pulmonary inflammation in patients without preexisting lung injury. Anesthesiology 108(1):46-54

22. Rotman V, Carvalho AR, Rodrigues RS, Medeiros DM, Pinto EC, Bozza FA, Carvalho CRR (2016) Effects of the open lung concept following ARDSnet ventilation in patients with early ARDS. BMC Anesthesiol 16(1):40

23. Jozwiak M, Teboul JL, Monnet X (2015) Extravascular lung water in critical care: recent advances and clinical applications. Ann Intensive Care 5(1):38

24. Gattinoni L, Cressoni M, Brazzi L (2014) Fluids in ARDS: from onset through recovery. Curr Opin Crit Care 20(4):373-377

Submit your manuscript to a SpringerOpen ${ }^{\odot}$ journal and benefit from:

- Convenient online submission

- Rigorous peer review

- Open access: articles freely available online

- High visibility within the field

- Retaining the copyright to your article

Submit your next manuscript at $\boldsymbol{\nabla}$ springeropen.com 